\title{
1 Solvent Water Controls Photocatalytic Methanol Reforming
}

2 Bei-Bei Xu, ${ }^{[1]}$ Min Zhou, ${ }^{,[2]}$ Ran Zhang, ${ }^{[1]}$ Man Ye, ${ }^{[1]}$ Ling-Yun Yang, ${ }^{[3]}$ Rong Huang, ${ }^{[4]}$ Hai Feng Wang, ${ }^{*[2]}$

3 Xue Lu Wang, ${ }^{*[1]}$ Ye-Feng Yao*[I]

$4 \quad{ }^{1}$ Physics Department \& Shanghai Key Laboratory of Magnetic Resonance, School of Physics and Electronic

5 Science, East China Normal University, North Zhongshan Road 3663, Shanghai 200062, P. R. China

$6 \quad{ }^{2}$ Key Laboratory for Advanced Materials, Centre for Computational Chemistry and Research Institute of

7 Industrial Catalysis, East China University of Science and Technology, Shanghai, 200237, China

$8 \quad{ }^{3}$ iHuman Institute, ShanghaiTech University, Shanghai 201210, China

$9 \quad{ }^{4}$ Department of Electronic Engineering, School of Physics and Electronic Science, East China Normal

10 University, North Zhongshan Road 3663, Shanghai 200062, P. R. China

11 Corresponding Authors:

12 hfwang@ecust.edu.cn; xlwang@phy.ecnu.edu.cn; yfyao@phy.ecnu.edu.cn

14 Material synthesis and characterization. The $\mathrm{Pt}(3.0 \mathrm{wt} \%) / \mathrm{TiO}_{2}$ photocatalyst powder was synthetized 15 by the co-precipitation method. An appropriate amount of $\mathrm{H}_{2} \mathrm{PtCl}_{4}$ aqueous solution ( $1 \mathrm{wt} \%$ ) was added 16 into the $\mathrm{TiO}_{2}\left(100 \mathrm{mg}\right.$, Anatase, Sigma) powder and maintained at $80^{\circ} \mathrm{C}$ for $1 \mathrm{~h}$. After dried, the sample 17 was calcined at $300^{\circ} \mathrm{C}$ for $2 \mathrm{~h}$. Prior to being characterized and tested, the sample was reduced in $20 \%$ $18 \mathrm{H}_{2} / \mathrm{Ar}$ at $300^{\circ} \mathrm{C}$ for $1 \mathrm{~h}$. Next, the structures of the Pt-Anatase (101) were characterized by x-ray diffraction 19 (XRD, Rigaku Ultima IV X-ray Diffractometer with $\mathrm{Cu}-\mathrm{K} \alpha$ radiation $(\mathrm{V}=35 \mathrm{kV}, \mathrm{I}=25 \mathrm{~mA}, \lambda=1.5418$ $20 \AA)$ ), and the angular range was $5-90^{\circ}$ with a scanning rate of $10^{\circ} \mathrm{min}^{-1}$. A scanning electron microscope 21 (SEM, Hitachi S-4800) and energy dispersive spectrometer (EDS) were used to characterize the morphology of the sample (see Supplementary Information, Figures S11 to S13).

23 NMR experiments. The operando NMR set-up for the study of the solid-liquid heterogeneous 24 photocatalytic reaction (Figures S14) in this work has been described previously in detail ${ }^{1}$. The samples 25 (a suspension containing Pt-Anatase photocatalyst together with the pure $\mathrm{CH}_{3} \mathrm{OH}$ or $\mathrm{CH}_{3} \mathrm{OH}+$ bulk $\mathrm{H}_{2} \mathrm{O}$ 26 binary solution) were prepared in NMR tubes at room temperature and atmospheric pressure, allowing 
the liquid phase reactions with a solid catalyst of the systems to be directly studied inside the NMR probe. In order to disperse $\mathrm{TiO}_{2}$ powders uniformly in the solvent, an ultrasonication process (10 min) was applied on the NMR tubes. After the ultrasonic dispersion process, the $\mathrm{TiO}_{2}$ suspension looks like a milklike liquid and a white ring was formed and attached on the tube wall on the top of the milk-like liquid. This white ring is formed by the very fine $\mathrm{TiO}_{2}$ powder and might change a little bit after the sample was kept for a long time (see Figures S15). The prepared samples were irradiated with a $300 \mathrm{~W}$ Xe lamp with different wavelength filters by using optical fiber (including $350 \mathrm{~nm}, 365 \mathrm{~nm}, 380 \mathrm{~nm}, 400 \mathrm{~nm}, 420 \mathrm{~nm}$, $450 \mathrm{~nm}$ and $500 \mathrm{~nm}$ filters, Beijing Perfectlight Science and Technology Co., Ltd.). The methanol $\left(\mathrm{CH}_{3} \mathrm{OH}, 99.9 \%\right)$ was obtained from Sigma-Aldrich, methanol- $\mathrm{D}_{4}\left(\mathrm{CD}_{3} \mathrm{OD}, 99.9 \%\right)$ with $0.03 \% \mathrm{~V} / \mathrm{V}$ TMS solvents was obtained from Cambridge Isotope Lab, and deuterium oxide $\left(\mathrm{D}_{2} \mathrm{O}, 99.9 \%\right.$ atom $\mathrm{D}$, containing $0.05 \%$ wt. 3-(trimethylsilyl)propionic-2,2,3,3- $\mathrm{d}_{4} \mathrm{acid}$ ) was obtained from Sigma-Aldrich. The necessary benchmark experiments were conducted before qualitatively and quantitatively detecting products in the solid-liquid mixtures so that the signals had a good signal-to-noise ratio (SNR) and could be distinctly distinguished on a Bruker AV-800 spectrometer $(18.8 \mathrm{~T})$ and Varian $700 \mathrm{M}$ spectrometer $(16.4 \mathrm{~T})$. These experimental conditions could provide the capability to probe the solid/liquid mixture products quantitatively. The data processing of the NMR spectra was performed using the Bruker software TopSpin.

Gas chromatography experiments. The hydrogen product from the aqueous methanol solution was analyzed by gas chromatography (Shanghai Ruimin Instrument Co.,Ltd., GC-2060) with thermal conductivity detector (TCD). The carrier gas was high purity argon gas. The temperature conditions of GC were $150^{\circ} \mathrm{C}, 80^{\circ} \mathrm{C}$ and $150^{\circ} \mathrm{C}$ for injection, column and detector.

Calculation details. All the spin-polarized calculations were performed using the Perdew-BurkeErnzerhof (PBE) functional ${ }^{2}$ within the generalized gradient approximation $(\mathrm{GGA})^{3}$, and implemented in the Vienna Ab-initio Simulation Package (VASP) ${ }^{4,5}$ code. The project-augmented wave (PAW) method ${ }^{6}$ was used to represent the core-valence electron interaction, and the valence electronic states were expanded in plane wave basis sets with a cutoff energy of $450 \mathrm{eV}$. The van der Waals interactions were considered using the DFT-D3 method ${ }^{7}$. We constructed a p $(2 \times 3)$ unit cell with $3 \mathrm{TiO}_{2}$ slabs and a $\mathrm{Pt}_{8}$ cluster to model anatase $\mathrm{TiO}_{2}$ (101) with deposited $\mathrm{Pt}_{8}$ (Figure S9). The bottom layer was fixed during calculations, and the separated vacuum layer was $13 \AA .(2 \times 2 \times 1)$ and $(5 \times 5 \times 1)$ k-point meshes were utilized for all structure optimizations and single point energy calculations, respectively. Note that, for some elementary reactions (path $\mathrm{I}, \mathrm{CH}_{3} \mathrm{OH}$ and $\mathrm{H}_{2} \mathrm{O}$ dissociation), a $\mathrm{p}(4 \times 3)$ unit cell with $3 \mathrm{TiO}_{2}$ slabs and a $(1 \times 1 \times 1)$ k-point mesh was used. Notably, we have fully tested the effect of the slab thickness on 
the computational accuracy. Taking $\mathrm{CH}_{3} \mathrm{O}+\mathrm{CH}_{3} \mathrm{O} \rightarrow \mathrm{CH}_{3} \mathrm{OH}+\mathrm{CH}_{2} \mathrm{O}$ as an example, the results

2 illustrate that, when there are three $\mathrm{TiO}_{2}$-unit layers, the barrier of $\mathrm{CH}_{3} \mathrm{O}$ activation is $0.83 \mathrm{eV}$ and 3 enthalpy change is $0.00 \mathrm{eV}$; when there are four layers, the activation energy is $0.85 \mathrm{eV}$ and enthalpy 4 change is $0.02 \mathrm{eV}$. Therefore, the number of layers has little effect on the calculation results. All the 5 transition states (TSs) were searched by a constrained optimization scheme ${ }^{8,9}$ and the convergence of 6 force was set to $0.05 \mathrm{eV} / \AA$.

7 For the Pt-TiO 2 system, it is widely believed that the DFT with the Hubbard U method can yield similar 8 electronic structures to those from the hybrid DFT (HSE06 functional) calculations with the merit of a 9 reasonable time consumption. We applied the $\mathrm{DFT}+\mathrm{U}$ method to compute the electronic properties of Pt$10 \mathrm{TiO}_{2}$, such as the Bader charges and density of states (DOSs), where the on-site coulomb corrections were 11 set on $\mathrm{Ti} 3 \mathrm{~d}$ and $\mathrm{O} 2 \mathrm{p}$ orbitals with the effective $\mathrm{U}$ term of $4.2 \mathrm{eV}$ and $6.3 \mathrm{eV}$, respectively, as suggested 12 in previous works.

13 The adsorption energies of the pertinent adsorbates were defined as follows:

$14 \quad E_{\text {ads }}=E_{\text {(adsorbate/surface) }}-E_{\text {(adsorbate) }}-E_{\text {(surface), }}$

15 where $E_{\text {(adsorbate/surface) }}, E_{\text {(adsorbate), }}$, and $E_{\text {(surface) }}$ are the total energies of the adsorbate binding to the surface, 16 free adsorbate in the gas phase, and clean surface, respectively. Notably, for the adsorption/desorption 17 processes, the large entropy contributions of gaseous molecules $(T \Delta S)$, including the vibrational, 18 rotational, and translational entropies, have to be considered to estimate $\Delta G$ at a temperature of $298 \mathrm{~K}$. 19 The Gibbs free energy change $(\Delta G)$ of the adsorption/desorption processes was estimated according to $20 \Delta G=\Delta H-T \Delta S$. The reaction enthalpy $\Delta H$ was approximated with the total energy difference $(\Delta E)$ 21 neglecting the small zero-point energy correction $(\triangle Z P E)$, heat capacity correction, and $\Delta(p V)$ term ${ }^{10}$. All the desorption energies of atomic hydrogens were calculated using $\mathrm{H}_{2}$ as the reference.

To simulate the actual reaction environment, the molecular dynamics (MD) calculations were performed using the model with $3 \mathrm{Pt}-\mathrm{TiO}_{2}$ layers, in which lattice-matching pure bulk ice (containing $24 \mathrm{H}_{2} \mathrm{O}$ molecules) and 1-methanol-containing bulk ice (including $29 \mathrm{H}_{2} \mathrm{O}$ and $1 \mathrm{CH}_{3} \mathrm{OH}$ molecules) were applied above the surface as an initial aqueous network at the liquid/solid interface. Only the $\Gamma$ point was used to sample the Brillouin zone. The simulation temperature was set to $300 \mathrm{~K}$ (experimental temperature) with a 0.5 fs movement for each step in the canonical (NVT) ensemble employing Nosé-Hoover thermostats. More than 10 ps MD simulations were performed, and all the simulations reach the equilibrium plateau after $\sim 2.5$ ps (Figure S10). 


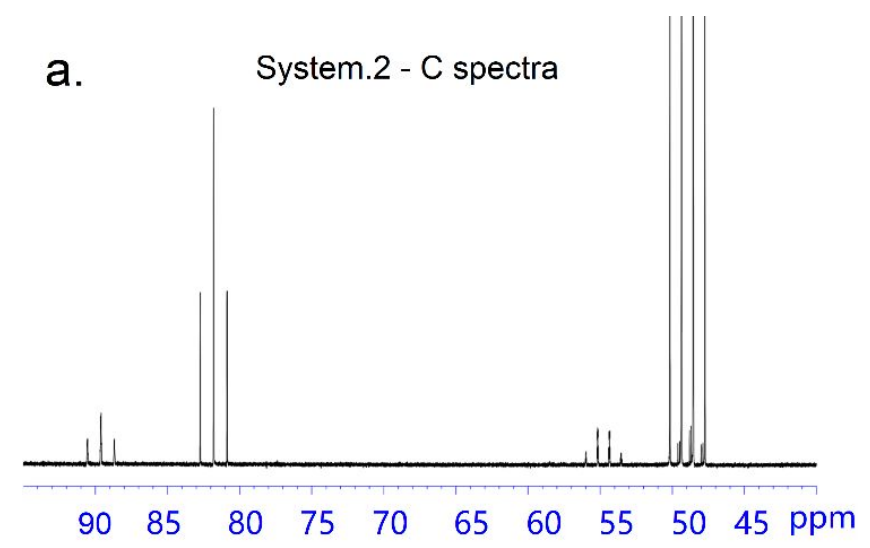

b.

System.2 - DEPT
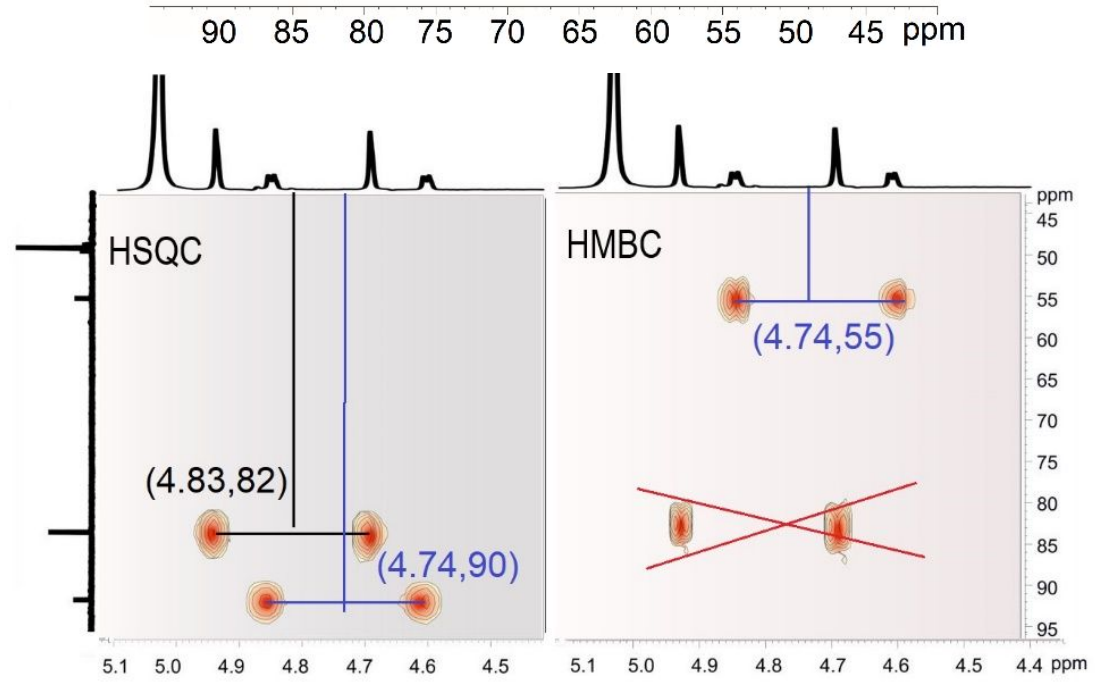

6

7 Supplementary Figure S1. DEPT, HSQC and HMBC spectrums were applied to assign the photocatalytic products,

8 which were acquired from System 2: $\mathrm{D}_{2} \mathrm{O}(500 \mu \mathrm{L})+{ }^{13} \mathrm{CH}_{3} \mathrm{OH}(20 \mu \mathrm{L})+\mathrm{Pt} /$ Anatase- $\mathrm{TiO}_{2}(1 \mathrm{mg})$ using ${ }^{13} \mathrm{C}$ labeled 9 methanol as the sacrificial agent. 
A series of experiments were carried out on the solid-liquid mixtures after irradiation, such as $\mathrm{C}$ 2 spectra, DEPT (Distortionless Enhancement by Polarization Transfer), ${ }^{1} \mathrm{H}-{ }^{13} \mathrm{C}$ HSQC (Heteronuclear 3 Singular-Quantum Correlation), ${ }^{1} \mathrm{H}-{ }^{13} \mathrm{C}$ HMBC (Heteronuclear Multiple-Bond Correlation) as shown in 4 Figure S1. All samples were labeled by ${ }^{13} \mathrm{C}$ isotope in order to enhance the NMR signals. Different kinds 5 of carbon atoms such as methyl $\left(-\mathrm{CH}_{3}\right)$ and methylene $\left(-\mathrm{CH}_{2}\right)$ can be distinguished by Carbon spectra and 6 DEPT spectra. Among them, the signals of $49 \mathrm{ppm}$ and $55 \mathrm{ppm}$ were corresponded to $-\mathrm{CH}_{3}$ groups, 82 $7 \mathrm{ppm}$ and $90 \mathrm{ppm}$ were corresponded to $-\mathrm{CH}_{2}$ groups. In order to ascribe the correlation between the 8 protons and attached carbons, ${ }^{1} \mathrm{H}_{-}{ }^{13} \mathrm{C}$ HSQC and ${ }^{1} \mathrm{H}-{ }^{13} \mathrm{C}$ HMBC experiments were carried out on the 9 System.2. As shown in HSQC spectrum, the proton of 4.74 ppm was directly attached to 90 ppm carbon $10\left(-\mathrm{CH}_{2}\right)$ and the $4.83 \mathrm{ppm}$ was directly attached to $82 \mathrm{ppm}$ carbon $\left(-\mathrm{CH}_{2}\right)$ in the HSQC spectrum, while 11 the $4.74 \mathrm{ppm}$ of proton was remotely attached to $55 \mathrm{ppm}$ carbon $\left(-\mathrm{CH}_{3}\right)$ through two-dimensional $\mathrm{HMBC}$ 12 spectra. Since the whole reaction system contained only two chemical regent $\mathrm{CH}_{3} \mathrm{OH} / \mathrm{H}_{2} \mathrm{O}$ and the 13 molecular fragments of photocatalytic products were also assigned by two-dimensional NMR spectra, the $14 \quad 4.74 \mathrm{ppm}$ signal in the spectra should correspond to methylene glycol $\left(\mathrm{HOCH}_{2} \mathrm{OH}\right.$ could be observed to 15 be remotely correlated with $-\mathrm{CH}_{2}$ and this was a residual single bond correlation that was not completely 16 filtered out in HMBC spectrum), and the signal of $4.83 \mathrm{ppm}$ should be assigned to hemiacetal $17\left(\mathrm{CH}_{3} \mathrm{OCH}_{2} \mathrm{OH}\right)$. 


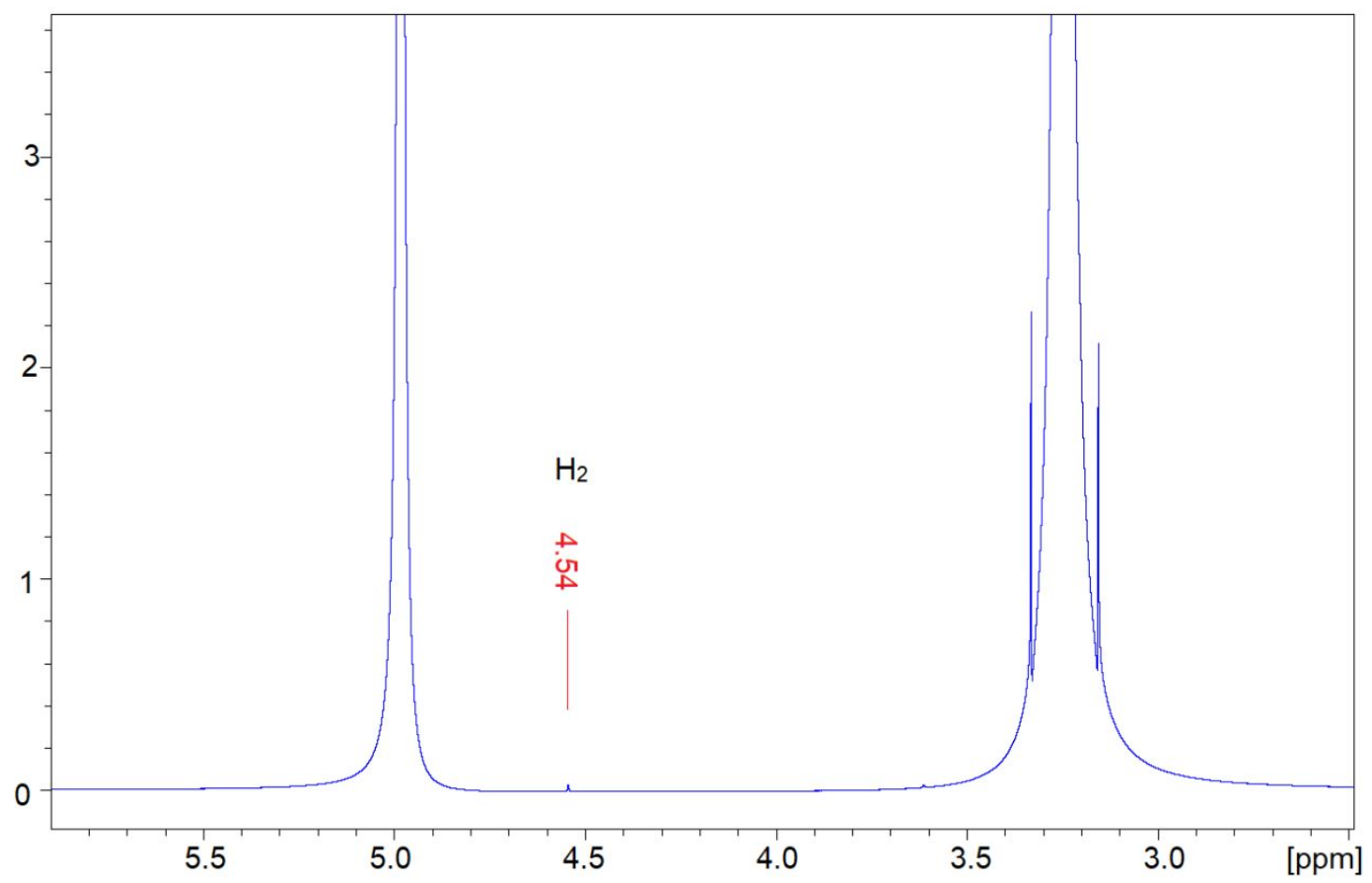

3

4 Supplementary Figure S2. ${ }^{1} \mathrm{H}$ NMR spectrum of sample containing $\mathrm{CD}_{3} \mathrm{OD}(250 \mu \mathrm{L})+\mathrm{CH}_{3} \mathrm{OH}(250 \mu \mathrm{L})+\mathrm{Pt} /$ Anatase$5 \quad \mathrm{TiO}_{2}(1 \mathrm{mg})$ suspensions with $420 \mathrm{~nm}$ wavelength after 4 hours.

6 


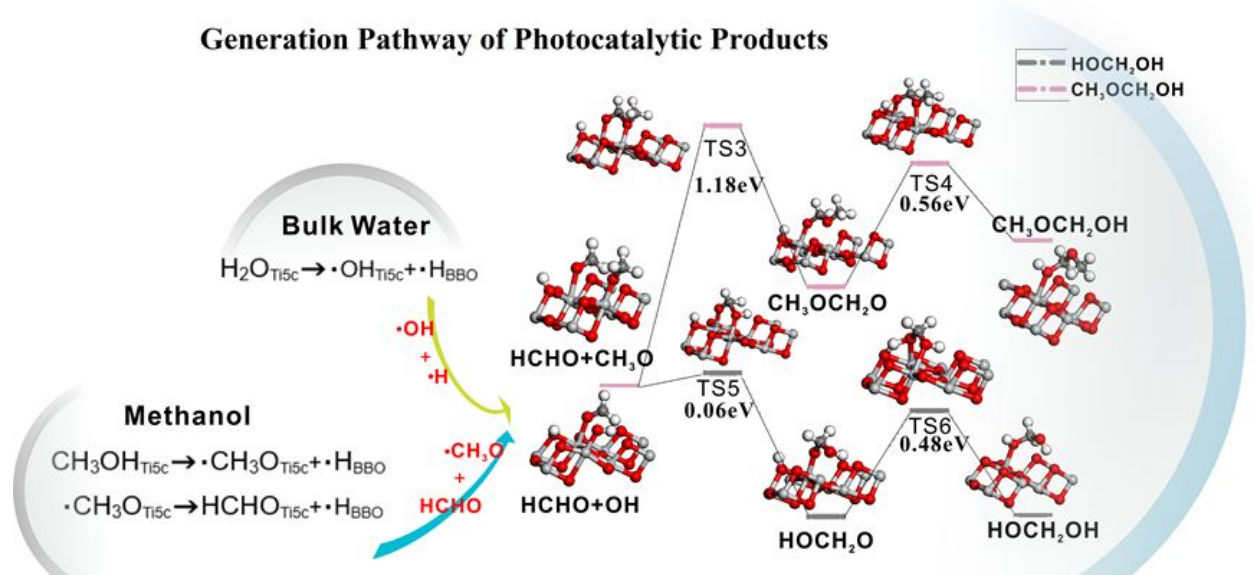

6 Supplementary Figure S3. Optimized structures and calculated potential energy profiles of the relevant steps involved 7 in the direct mechanism for $\mathrm{CH}_{3} \mathrm{OH}$ dissociation into $\mathrm{HCHO}, \mathrm{HCHO} / \mathrm{OH}$ oxidized into $\mathrm{HOCH}_{2} \mathrm{OH}$ and $\mathrm{HCHO} / \mathrm{CH}_{3} \mathrm{O}$ 8 oxidized into $\mathrm{CH}_{3} \mathrm{OCH}_{2} \mathrm{OH}$ products at the Ti5c sites on the Pt-Anatase (101) surface. The structures of transition states 9 in each step are shown as well (TS3 to TS6), noted that the Ti atoms are in light grey and $\mathrm{O}$ in red, the $\mathrm{C}$ atoms are in 10 dark grey and $\mathrm{H}$ in white. 


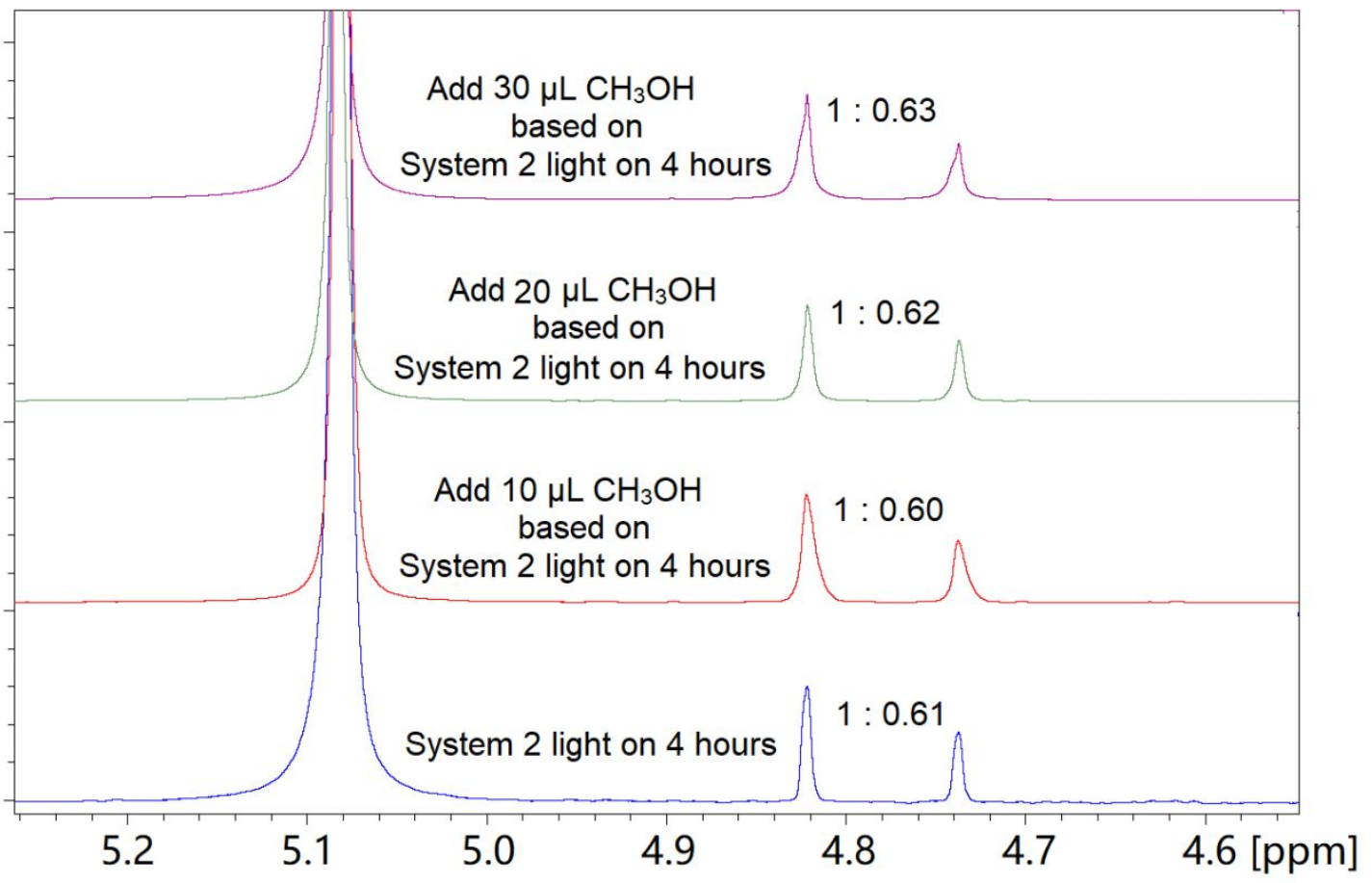

5 Supplementary Figure S4. The ${ }^{1} \mathrm{H}$ NMR spectra of methylene glycol and hemiacetal after being introduced extra $6 \quad \mathrm{CH}_{3} \mathrm{OH}$. Noted that the catalyst of System 2 has been filtered out after irradiation.

8 We also consider the reaction occurring in the solution, such as the possible dehydration reaction of 9 methyl glycol and methanol to form hemiacetal. To check this dehydration reaction in solution, we 10 introduced $10 \mathrm{ml}, 20 \mathrm{ml}$ and $30 \mathrm{ml}$ methanol into System 2 (containing $\mathrm{HOCH}_{2} \mathrm{OH}$ and $\mathrm{CH}_{3} \mathrm{OCH}_{2} \mathrm{OH}$ ) 11 in turn. The ratio of signal integrals of existing methylene glycol and hemiacetal did not change compared 12 to the origin ratio of System 2. That is, hemiacetal was probably not formed by condensation of methylene 13 glycol with methanol in our sample. 


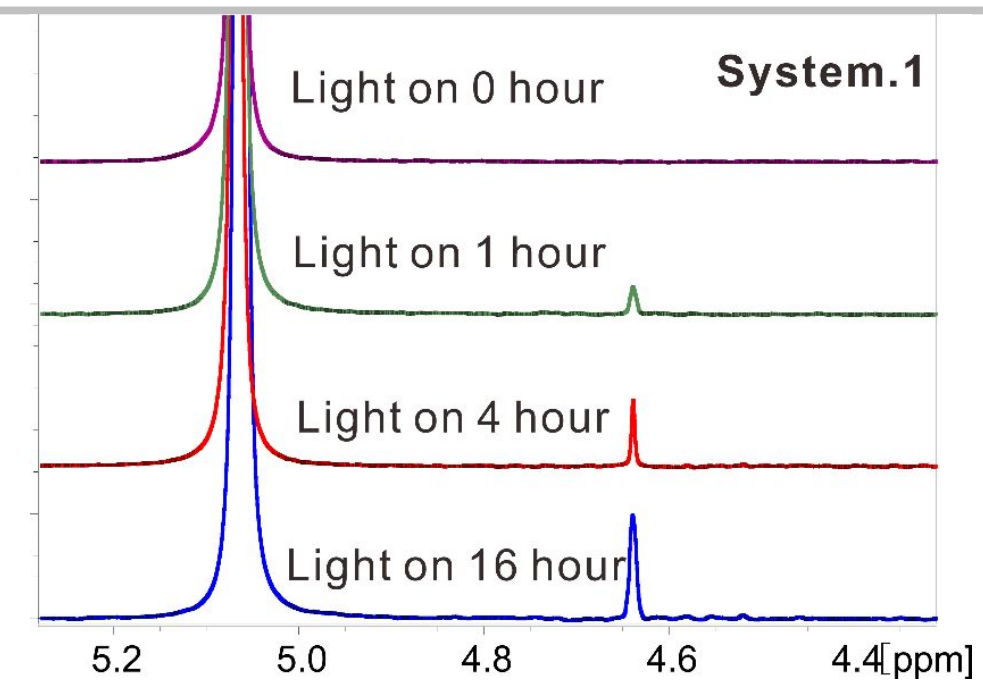

3 Supplementary Figure S5. ${ }^{1} \mathrm{H}$ NMR spectra of sample containing $\mathrm{CD}_{3} \mathrm{OD}(500 \mu \mathrm{L})+\mathrm{CH}_{3} \mathrm{OH}(20 \mu \mathrm{L})+\mathrm{Pt} /$ Anatase$4 \quad \mathrm{TiO}_{2}(1 \mathrm{mg})$ suspensions with $365 \mathrm{~nm}$ wavelength. 

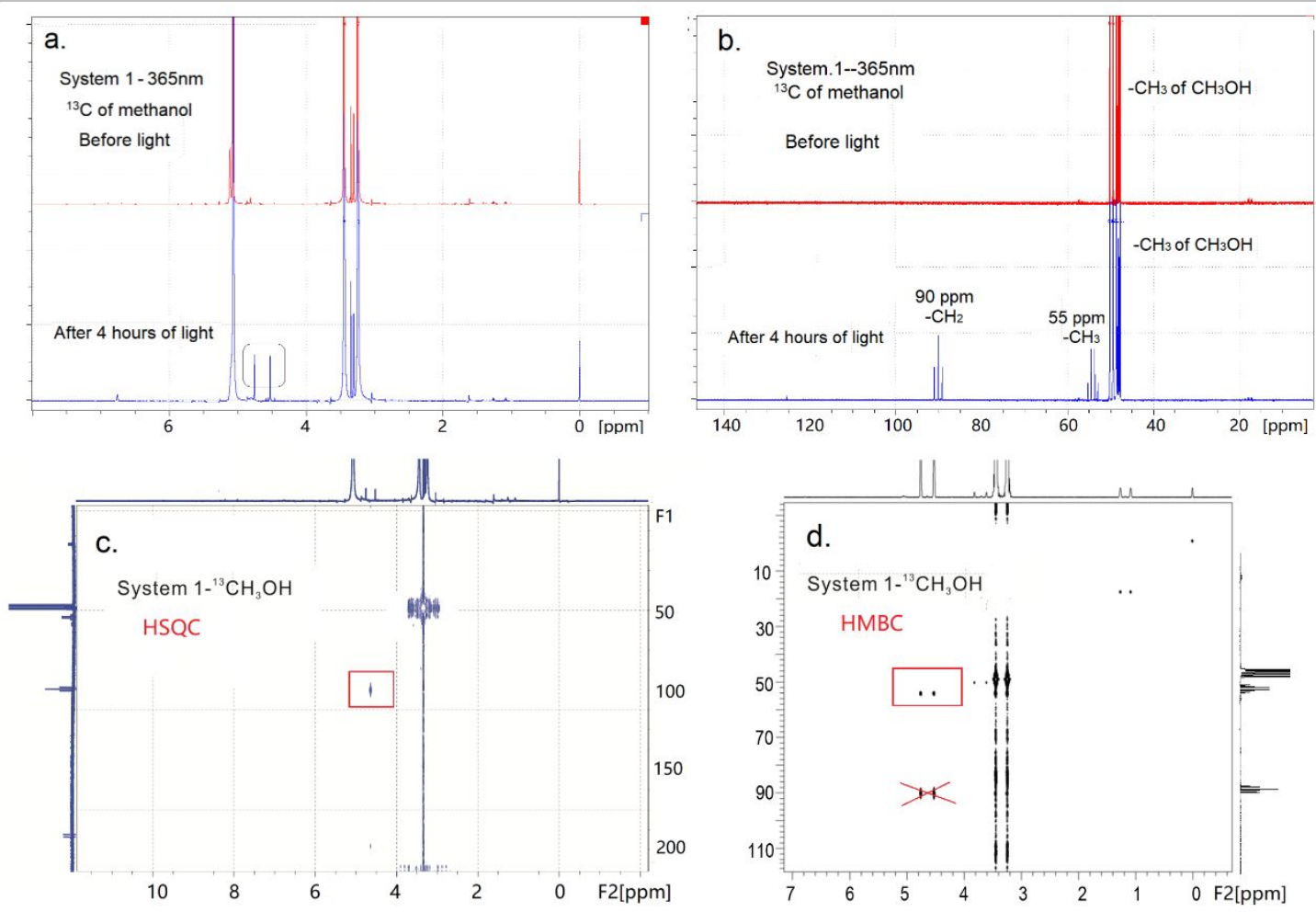

\begin{tabular}{|c|c|c|c|c|}
\hline & ${ }^{1} \mathrm{H}$ spectra $\left(\delta_{H}\right)$ & $\mathrm{HSQC}\left(\delta_{C}\right)$ & $\operatorname{HMBC}\left(\delta_{C}\right)$ & DEPT \\
\hline System.1 & 4.65 & $90\left(-\mathrm{CH}_{2}\right)$ & $55\left(-\mathrm{CH}_{3}\right)$ & $-\mathrm{CH}_{2}$ \\
\hline
\end{tabular}

3 Supplementary Figure S6. The assignment of $4.65 \mathrm{ppm}$ peak in System.1, using ${ }^{13} \mathrm{C}$ labeled methanol as the 4 sacrificial agent under $365 \mathrm{~nm}$ irradiation. (a) ${ }^{1} \mathrm{H}$ NMR spectrum of System $1\left(\mathrm{CD}_{3} \mathrm{OD} /{ }^{13} \mathrm{CH} / 3 \mathrm{OH} /\right.$ catalyst) before and 5 after the $365 \mathrm{~nm}$ irradiation. (b) Quantitative ${ }^{13} \mathrm{C}$ NMR spectrum of System.1 $\left(\mathrm{CD}_{3} \mathrm{OD} /{ }^{13} \mathrm{CH}_{3} \mathrm{OH} /\right.$ catalyst) before and 6 after the irradiation. The two spectra were acquired from samples containing $\mathrm{CD}_{3} \mathrm{OD}(500 \mathrm{ul}),{ }^{13} \mathrm{CH}_{3} \mathrm{OH}(20 \mathrm{ul})$ and Pt$7 \quad \mathrm{TiO}_{2}(1 \mathrm{mg})$ at $275 \mathrm{~K}$ with a $200 \mathrm{~s}$ recycle delay and 500 scans. (c)(d) ${ }^{1} \mathrm{H}-{ }^{13} \mathrm{C}$ HSQC (Heteronuclear Singular-Quantum 8 Correlation) and ${ }^{1} \mathrm{H}_{-}{ }^{13} \mathrm{C}$ HMBC (Heteronuclear Multiple-Bond Correlation) are applied to assign the photocatalytic 9 products of $4.65 \mathrm{ppm}$, which were acquired from System.1: $\mathrm{CD}_{3} \mathrm{OD}(500 \mu \mathrm{L})+{ }^{13} \mathrm{CH}_{3} \mathrm{OH}(20 \mu \mathrm{L})+\mathrm{Pt} /$ Anatase-TiO $_{2}(1$ $\mathrm{mg}$ ) using ${ }^{13} \mathrm{C}$ labeled methanol as the sacrificial agent.

12 In order to enhance the NMR signal, we used carbon-13-labelled ${ }^{13} \mathrm{CH}_{3} \mathrm{OH}$ instead of ${ }^{12} \mathrm{CH}_{3} \mathrm{OH}$. We can 13 observe the single signal (4.65 p.p.m.) disappear and split into doublets $\left({ }^{1} J_{\mathrm{CH}}=161.63 \mathrm{~Hz}\right)$, which verified 14 that the emerging ${ }^{1} \mathrm{H}$ signal came from methanol reforming product and hydrogen atoms of this product 15 was directly attached to carbon atom. As shown in Figure S1b, the signal of 49 ppm was corresponded to $16-\mathrm{CH}_{3}$ groupsa of original $\mathrm{CH}_{3} \mathrm{OH}$, the $55 \mathrm{ppm}$ and $90 \mathrm{ppm}$ were corresponded to $-\mathrm{CH}_{3}$ and $-\mathrm{CH}_{2}$ groups 17 of photocatalytic products, respectively. In order to ascribe the correlation between the protons and 18 attached carbons, ${ }^{1} \mathrm{H}-{ }^{13} \mathrm{C}$ HSQC and ${ }^{1} \mathrm{H}-{ }^{13} \mathrm{C}$ HMBC experiments were carried out on the System.1. As 19 shown in Figure S1c and S1d, the proton of 4.65 ppm was directly attached to 90 ppm carbon $\left(-\mathrm{CH}_{2}\right)$ in the HSQC spectrum, the $4.65 \mathrm{ppm}$ of proton was also remotely attached to $55 \mathrm{ppm}$ carbon $\left(-\mathrm{CH}_{3}\right)$ through 
1 two-dimensional HMBC spectra. As for the remotely correlated signal with $-\mathrm{CH}_{2}$, this is a residual single 2 bond correlation that is not completely filtered out in HMBC spectrum. More importantly, the quantitative $3{ }^{13} \mathrm{C}$ integral area of $-\mathrm{CH}_{2}(90 \mathrm{ppm})$ and the integral area of $-\mathrm{CH}_{3}(55 \mathrm{ppm})$ were 1.06 to 1 . Based on the 4 comprehensive consideration of above factors, we can deduce the reforming product was $\mathrm{CH}_{3} \mathrm{OCH}_{2} \mathrm{OH}$, 5 which was the a secondary product of $\mathrm{HCHO}$ intermediate. 


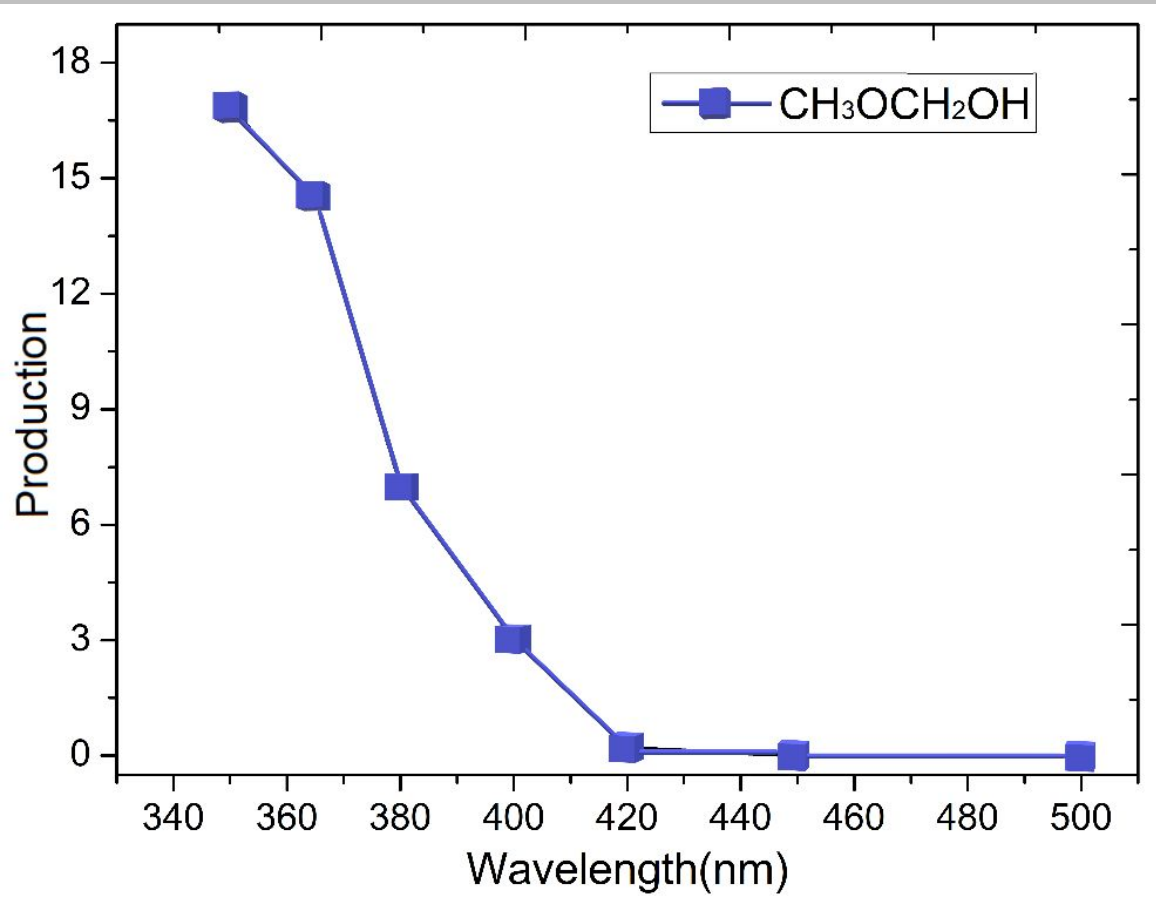

1 2

3 Supplementary Figure S7. Schematic diagram of $\mathrm{CH}_{3} \mathrm{OCH}_{2} \mathrm{OH}$ production varying with wavelength in System 1, 4 including $350 \mathrm{~nm}, 365 \mathrm{~nm}, 380 \mathrm{~nm}, 400 \mathrm{~nm}, 420 \mathrm{~nm}, 450 \mathrm{~nm}$ and $500 \mathrm{~nm}$ irradiation. 


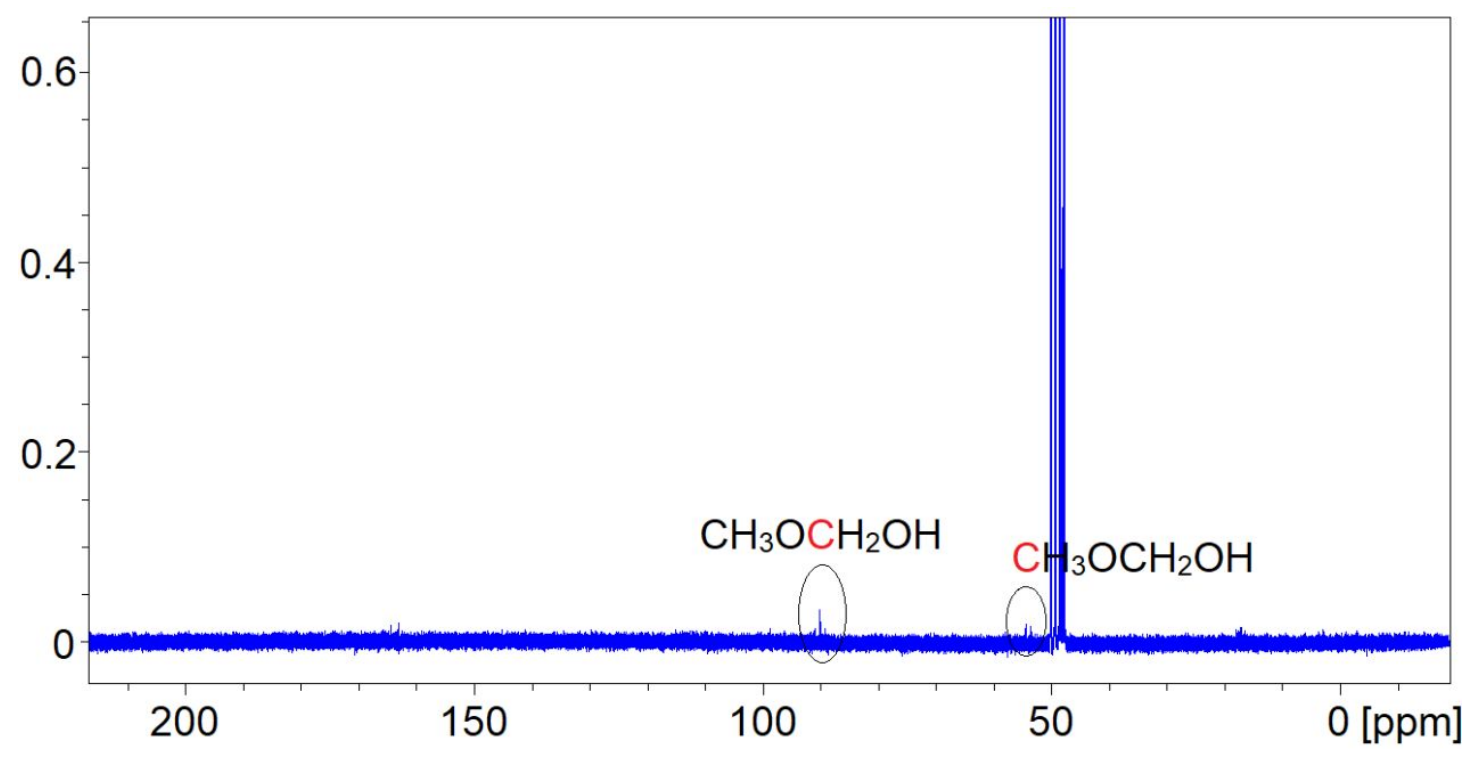

3

4 Supplementary Figure S8. ${ }^{13} \mathrm{C}$ NMR spectrum of sample containing ${ }^{13} \mathrm{CH}_{3} \mathrm{OH}(520 \mu \mathrm{L})+\mathrm{Pt} /$ Anatase- $\mathrm{TiO}_{2}(1 \mathrm{mg})$ 5 suspensions with $420 \mathrm{~nm}$ wavelength after 4 hours. 

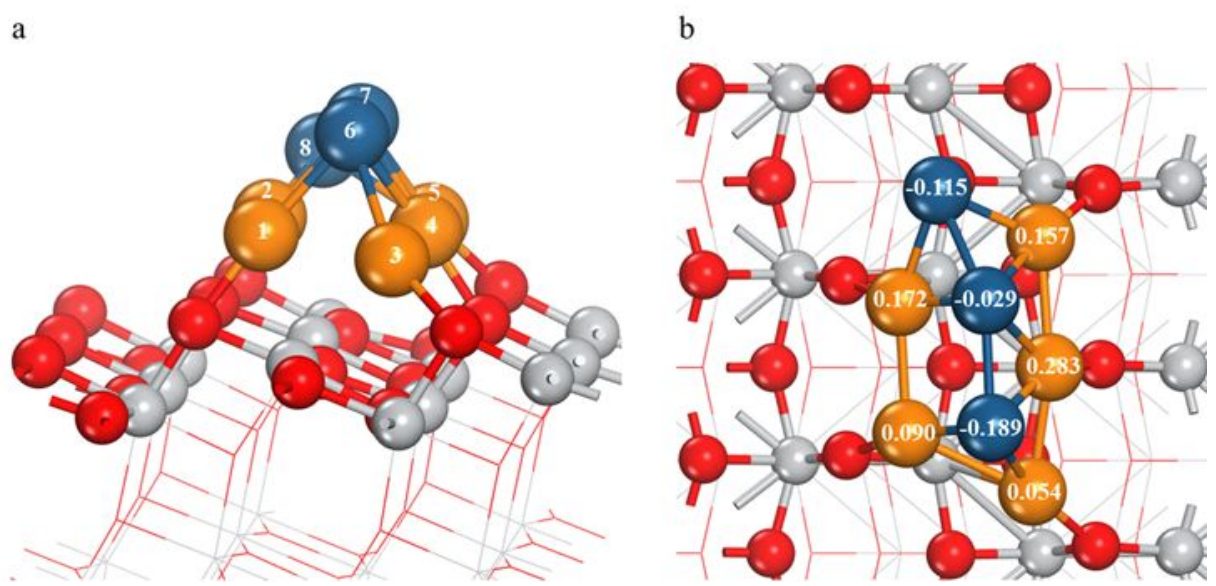

3 Supplementary Figure S9. Front (a) and top (b) views of the optimized structure of $\mathrm{Pt}_{8} / \mathrm{TiO}_{2}$ system. All $\mathrm{Pt}$ atoms are 4 indexed with Arabic numbers, and Bader charge of Pt is marked on each atom, respectively. Orange: bottom Pt; dark 5 cyan: top Pt.

7 The preliminary function of $\mathrm{Pt}$ is the well-known cocatalyst role, which provide superior active site for facilitating the $\mathrm{H}_{2}$ evolution reaction (see also our previous $\mathrm{Pt} / \mathrm{TiO}_{2}$ work ${ }^{11-13}$ ). Specifically, the $\mathrm{H}$ species generated from $\mathrm{CH}_{3} \mathrm{OH}$ or $\mathrm{H}_{2} \mathrm{O}$ dissociation would finally go to Pt cocatalyst and quickly form $\mathrm{H}_{2}$. Here, we used a 8-atom Pt cluster deposited on $\mathrm{TiO}_{2}(101)$ to model the $\mathrm{Pt} / \mathrm{TiO}_{2}(101)$. As shown in Figure $\mathrm{S} 9 \mathrm{a}$, $\mathrm{Pt}_{8}$ interacted strongly with $\mathrm{TiO}_{2}(101)$ with the bottom five $\mathrm{Pt}$ atoms $\left(\mathrm{Pt}_{1}-\mathrm{Pt}_{5}\right)$ anchoring to the surface through five Pt-O bonds. According to the Bader charge analysis (Figure S9b), these interface Pt atoms $\left(\mathrm{Pt}_{1-5}\right)$ are in fact $\mathrm{Pt}^{\delta+}$ species, while the topmost $\mathrm{Pt}\left(\mathrm{Pt}_{6-8}\right)$ are nearly $\mathrm{Pt}^{0 / \delta-}$. The adsorption energies of atomic $\mathrm{H}^{*}$ on $\mathrm{Pt}$ sites are $\sim-0.16(-0.81) \mathrm{eV}$ on $\mathrm{Pt}^{\delta+}\left(\mathrm{Pt}^{0 / \delta-}\right)$, corresponding to an adsorption free energy $\left(\Delta \mathrm{G}_{\mathrm{H}}\right)$ of $-0.01(-0.66) \mathrm{eV}$ at the $\mathrm{U}=\mathrm{U}_{\mathrm{SHE}}$ and $\mathrm{pH}=0$. One can see that the positive-valency $\mathrm{Pt}^{\delta+}$ gives the $\Delta \mathrm{G}_{\mathrm{H}}$ near the acknowledged optimal adsorption strength $\left(\Delta \mathrm{G}_{\mathrm{H}}=0 \mathrm{eV}\right)$ for HER, and thus constitutes the superior active site for catalyzing HER (see also our previous work ${ }^{12}$ ). Importantly, this result theoretically demonstrates that $\mathrm{TiO}_{2}$ supported $\mathrm{Pt}$ nanoparticles can function as an efficient cocatalyst for HER.

Meanwhile, we supplemented the contrast experiment of pure anatase system. The experimental results show that under $420 \mathrm{~nm}$ radiation, almost no hydrogen is observed in $\mathrm{CH}_{3} \mathrm{OH} /$ Anatase system, and its oxidation production is about $47 \%$ of $\mathrm{CH}_{3} \mathrm{OH} / \mathrm{Pt}$-Anatase system; after introducing bulk water, no hydrogen is detected in $\mathrm{CH}_{3} \mathrm{OH} / \mathrm{H}_{2} \mathrm{O} /$ Anatase system, and its oxidation production is about $52 \%$ of $\mathrm{CH}_{3} \mathrm{OH} / \mathrm{H}_{2} \mathrm{O} / \mathrm{Pt}$-Anatase system. It indicates that $\mathrm{Pt}$ can significantly promote catalytic activity of Anatase- $\mathrm{TiO}_{2}$ (especially hydrogen evolution), and the effect of bulk water on methanol cracking is easier to be seen under the irradiation of $420 \mathrm{~nm}$ wavelength 


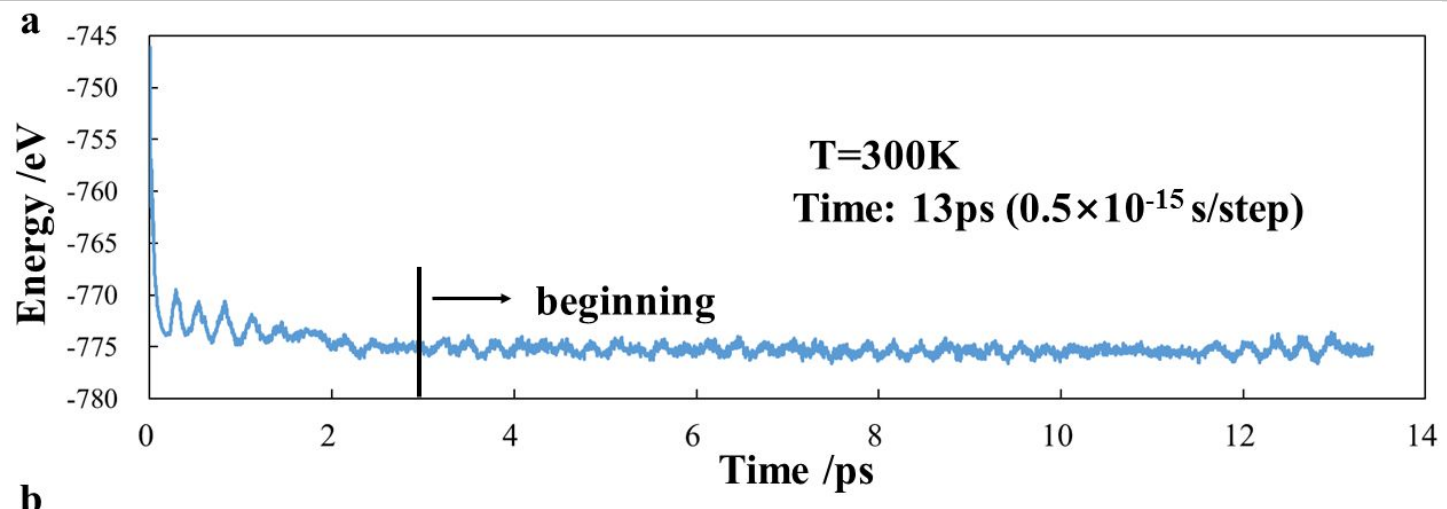

b

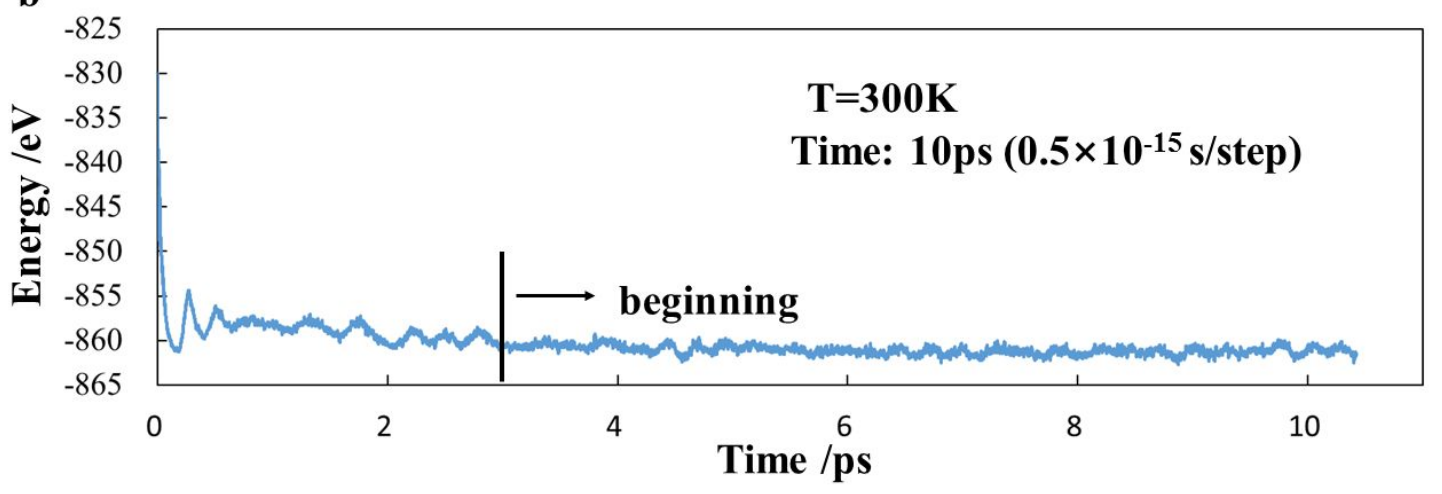

2

3 Supplementary Figure S10. Energy profile of MD simulation for water/ $\mathrm{TiO}_{2}(110)$ (a) and water $/ \mathrm{TiO}_{2}(110)$ containing 4 one $\mathrm{CH}_{3} \mathrm{OH}$ molecule (b). 


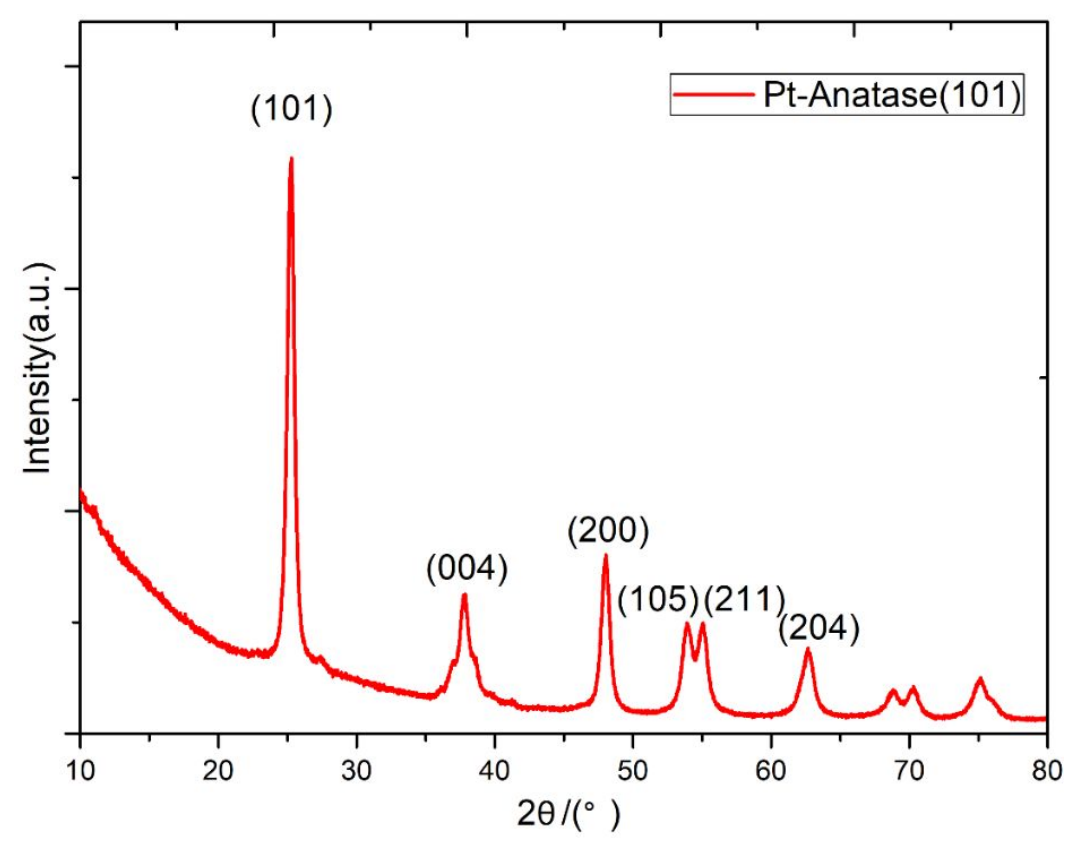

3

4 Supplementary Figure S11. XRD of Pt-Anatase (101) sample. 

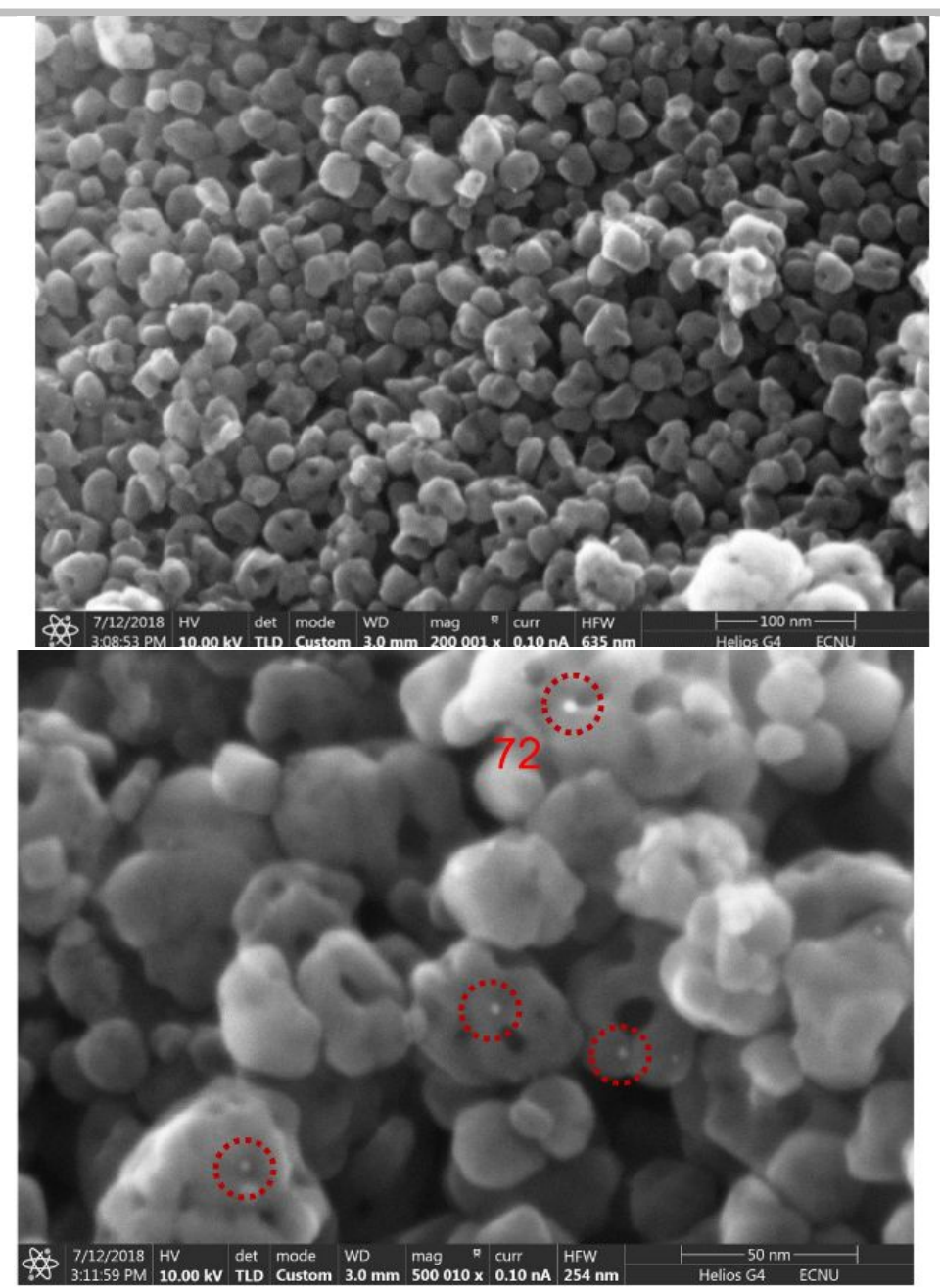

3

4 Supplementary Figure S12. SEM of Pt-Anatase (101) sample.

6 At low magnification (Left), we observe the nanocrystalline particles with the uniform size and irregular shape. At high magnification (Right), we observe the relatively bright nanoparticles loaded on the $\mathrm{TiO}_{2}$ 8 surface. 


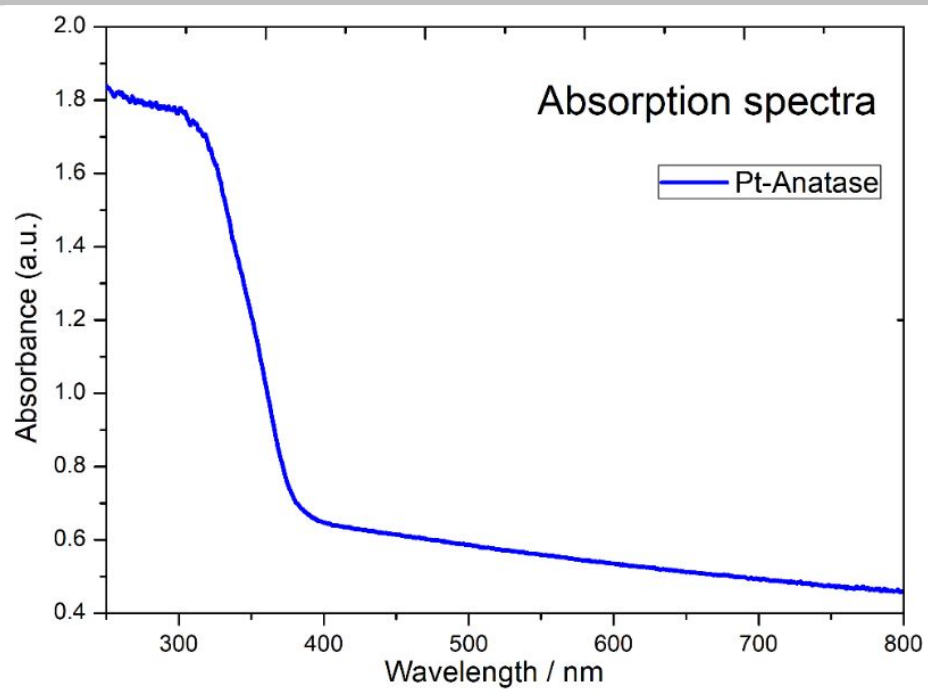

2

3 Supplementary Figure S13. Ultraviolet-visible spectroscopy of Pt-Anatase(101) sample.

4

5

6

7

8

9

10

11

12

13

14

15

16

17

18

19

20

21

22

23

24 


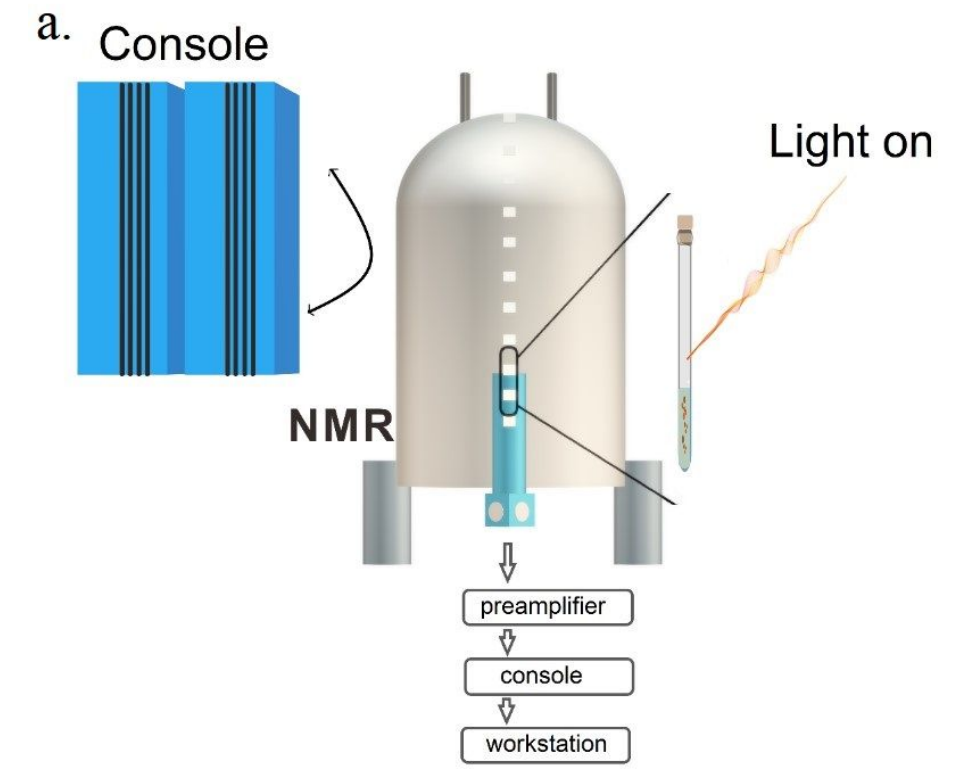

b.

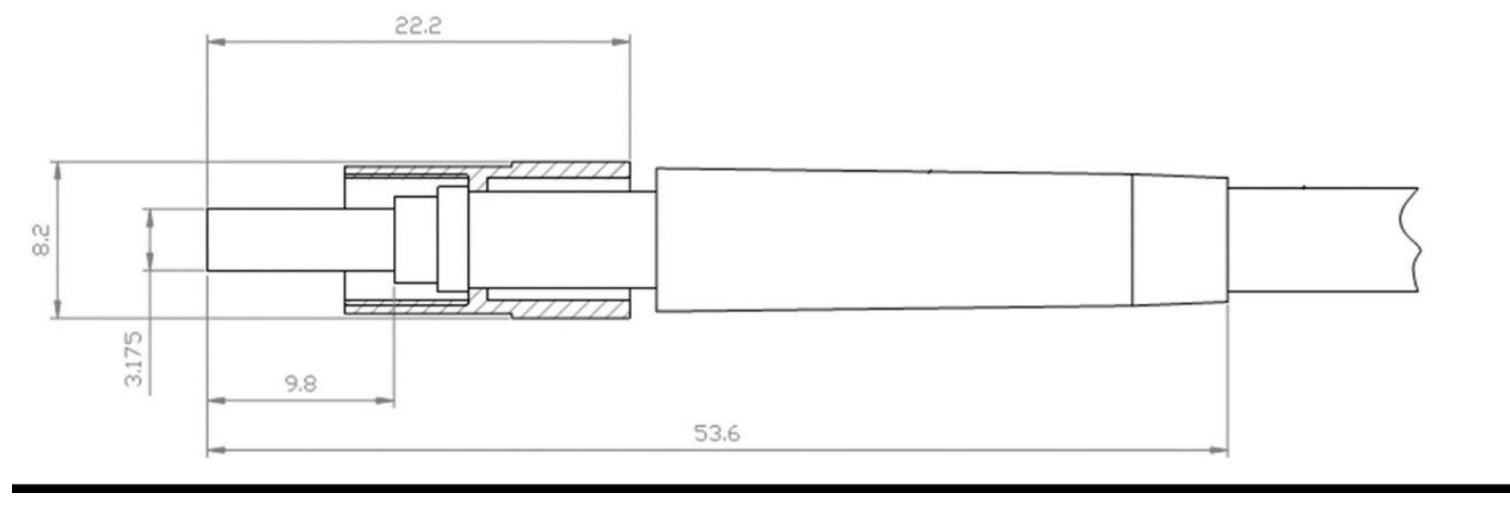

2

3

4

5

6 Supplementary Figure S14. a). Schematic set-up for operando NMR studies. b). The schematic diagram of the 7 homemade fibre. 

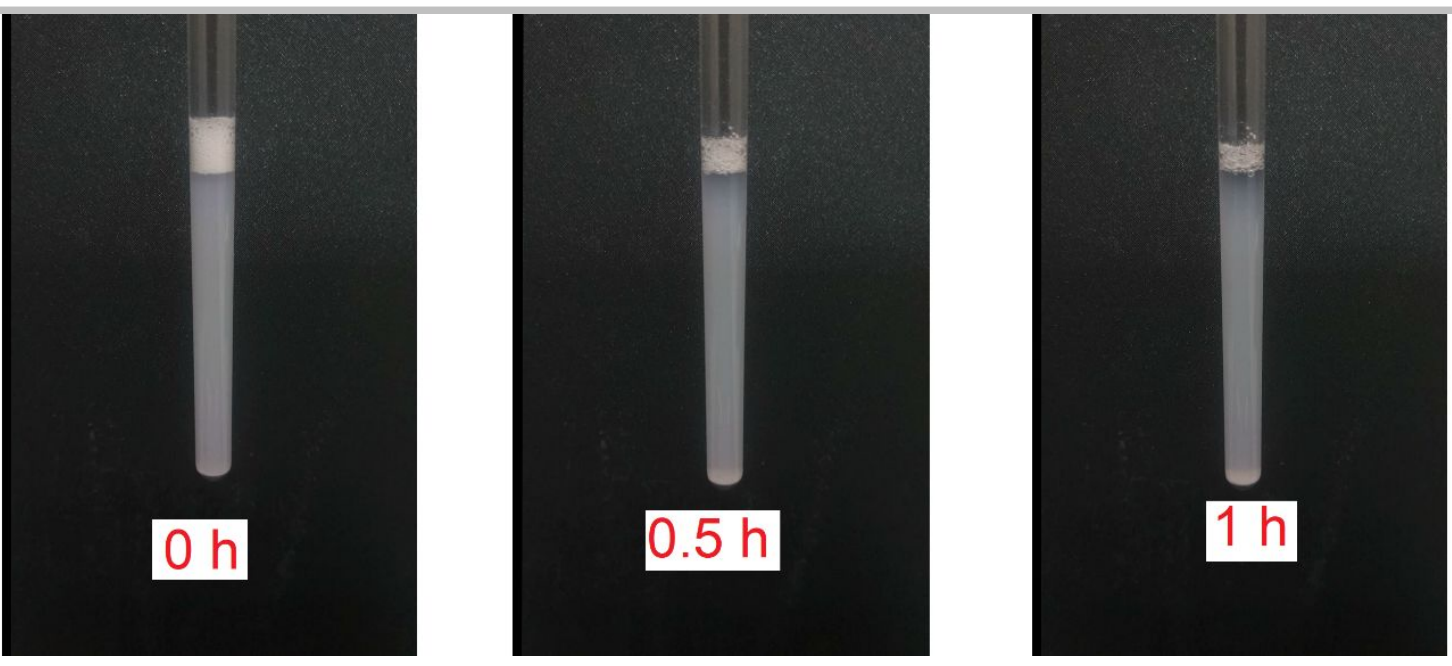

4 Supplementary Figure S15. Photos of a NMR tube containing the $\mathrm{TiO}_{2}$ powder suspension. These photos were taken 5 at the three observations points (i.e., $0,0.5$ and 1 hour). 


\section{References}

(1) Ye, M.; Xu, B.-B.; Zhang, R.; Yang, Y.-N.; Yang, L.-Y.; Wang, X. L.; Yao, Y.-F., Probing the methanol heterogeneous photochemistry processes by operando NMR-The role of bulk water. J. Catal. 2019, 378, 36-41.

(2) Perdew, J. P.; Ruzsinszky, A.; Csonka, G. I.; Vydrov, O. A.; Scuseria, G. E.; Constantin, L. A.; Zhou, X. L.; Burke, K. Restoring the density-gradient expansion for exchange in solids and surfaces. Phys. Rev. Lett. 2008, 100, 136406.

(3) Perdew, J. P.; Burke, K.; Ernzerhof, M. Generalized gradient approximation made simple. Phys. Rev. Lett. 1996, 77, 3865-3868.

(4) Kresse, G.; Furthmuller. J. Efficient iterative schemes for ab initio total-energy calculations using a plane-wave basis set. Phys. Rev. B. 1996, 54, 11169-11186.

(5) Kresse, G.; Furthmuller. J. Efficiency of ab-initio total energy calculations for metals and semiconductors using a plane-wave basis set. Comput. Mater. Sci. 1996, 6, 15-50.

(6) Kresse, G.; Joubert, D. From ultrasoft pseudopotentials to the projector augmented-wave method. Phys. Rev. B. 1999, 59, 1758-1775.

(7) Grimme, S.; Antony, J.; Ehrlich, S.; Krieg, H. A consistent and accurate ab initio parametrization of density functional dispersion correction (DFT-D) for the 94 elements H-Pu. J. Chem. Phys. 2010, 132, 154104.

(8) Jin, J.; Chen, J.; Wang, H.; Hu, P. Insight into room-temperature catalytic oxidation of NO by $\mathrm{CrO}_{2}(110)$ : A DFT study. Chin. Chem. Lett. 2019, 30, 618-623.

(9) Yuan, H.; Sun, N.; Chen, J.; Jin, J.; Wang, H.; Hu, P. Insight into the $\mathrm{NH}_{3}$-assisted selective catalytic reduction of $\mathrm{NO}$ on $\beta-\mathrm{MnO}_{2}$ (110): reaction mechanism, activity descriptor, and evolution from a pristine state to a steady state. ACS Catal. 2018, 8, 9269-9279.

(10) Jin, J.; Sun, N.; Hu, W.; Yuan, H.; Wang, H.; Hu, P. Insight into room-temperature catalytic oxidation of nitric oxide by $\mathrm{Cr}_{2} \mathrm{O}_{3}$ : A DFT study. ACS Catal. 2018, 8, 5415-5424.

(11) Li, Y.; Xing, J. Unidirectional suppression of hydrogen oxidation on oxidized platinum clusters. Nat. Commun. 2013, 4, 2500.

(12) Xing, J.; Jiang, H. Active sites on hydrogen evolution photocatalyst. J. Mater. Chem. A. 2013, 1, 15258-15264.

(13) Xing, J.; Chen, J. Stable isolated metal atoms as active sites for photocatalytic hydrogen evolution. Chem. Eur. J. 2014, 20, 2138-2144. 